\title{
Information technologies for solving urban construction problems
}

\author{
Elena Serova* \\ Moscow State University of Civil Engineering (MGSU) National Research University, 129337, \\ Moscow, Russia
}

\begin{abstract}
This study examines the options for using information technologies to solve the urban planning problems in order to improve their solutions' results quality. The analysis of the information technologies' use in solving urban planning problems is carried out, the systematization of the need to use certain information technologies, depending on the project development stage, is given. Variants of using certain information systems are considered in detail on the example of designing transport infrastructure facilities. The information technologies development influence levels on improving the quality of solving urban planning problems are determined.
\end{abstract}

\section{Introduction}

The information technology level development makes it possible to solve the issues of urban planning more efficiently, provided that the correct choice of information systems for solving the task at hand has been made. The need to use modern information technology capabilities to solve urban planning problems is due to increased requirements for the quality and speed of making design decisions.

\section{Main part}

Within the framework of this study, we will present the implementation of the processes for solving urban planning problems in the form of a diagram (Fig. 1). When solving urban planning problems (UPP) certain processes are performed using information technology (IT) to obtain the highest quality result.

The main urban planning tasks (UPP)are:

- State analysis of the existing condition of the territory;

- Planning and forecasting of the territorial development;

- Visual presentation of research results.

Processes for solving urban planning problems:

- Development of strategies for the territorial development;

- Development of urban planning documentation.

\footnotetext{
*Corresponding author: SerovaEA@mgsu.ru
} 
Information Technology (IT) for solving urban planning problems:

- IT for visual representation of the territory;

- IT for territory analysis;

- IT to predict the territorial development.

The results of solving urban planning problems can be presented in the form:

- Geographic information system(GIS);

- Iinformation model of the territory.

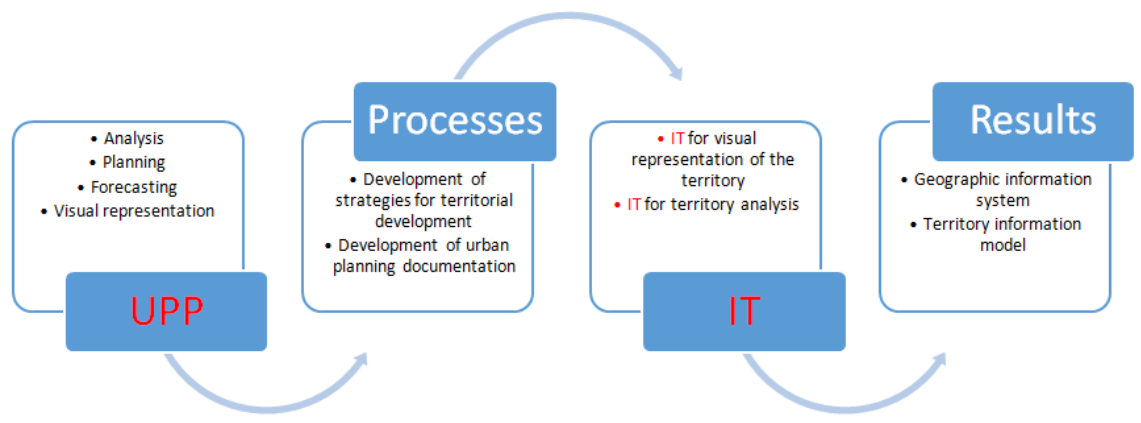

Fig. 1. Execution of processes for solving urban planning problems

In the scientific literature, various definitions of the geographic information system are used (GIS):

GIS-is an information system that provides collection, storage, processing, access, display and distribution of space-coded data [1];

GIS-is a set of hardware and software systems representing a geographic information service [2].

To determine the information model of the territory, consider the following definitions from the regulatory and technical documentation $[3,4]$.

Digital information model (DIM) is an object-oriented parametric three-dimensional model that digitally represents the physical, functional and other characteristics of an object (or its individual parts) in the form of a set of information-rich elements. [3]

Engineering digital terrain model (EDTM) is aform of an engineering-topographic plan presentation in a digital object-spatial form for automated solution of engineering problems and design of construction objects. EDTM consists of a digital elevation model and a digital model of the situation. [3]

Consolidated digital model is a a digital information model of an object, consisting of separate digital information models / engineering digital terrain models (for example, for various disciplines or parts of a construction object), interconnected in such a way that making changes to one of the models does not lead to a change in others. [3]

Digital information model (three-dimensional model) is an electronic document as a part of a capital construction object information model (IMCCO), digitally object-spatial [4].

Information model of a capital construction object (IMCCO) is a set of interrelated information, documents and materials about a capital construction object, generated in electronic form at the stages of engineering surveys, architectural and construction design, construction, reconstruction, overhaul, operation and (or) demolition of a capital construction object. [4]

Element of a digital information modelis a digital representation of a part of a capital construction object or territory, characterized by attributive and geometric data. [4] 
To accomplish the tasks of this study, we will formulate our own definition of the territory information model, based on the above-listed definitions.

Information model of the territory is a digital model of the territory, which digitally represents information on the objects located in a given territory using geoinformation technologies.

The issue of creating an information model of the territory can be considered both within the territorial planning schemes' development framework and the territorial planning projects by the responsible subdivisions of the state and municipal authorities, and within the framework of the individual territories' investment projects development by private investment companies.

When developing an investment project for the separate territory development, the following stages of project development can be distinguished:

- The project concept stage;

- Design and working documentation development stage;

- Structural objects' construction stage;

- Operation stage.

At the project concept stage, it is necessary to analyze the existing situation (collect and analyze the initial data of the project, present the specified materials as high quality and understandable as possible). In the process of analyzing the existing situation, the following activities are carried out:

- Collection of information on the current state of the territory (conducting sociodemographic studies of the territory, conducting the necessary surveys and measurements);

- Analysis of the existing state;

- Creation of a model of the territory.

In terms of the use of geoinformation technologies for solving the problems of structuring and presenting information on the objects of the territory, such software systems as ArcGIS (a commercial software product of the ESRI company) and QGIS (free distribution information system) are used, which give an opportunity to create a geographic information system using cartographic materials and attributive information. Analysis of modern software products is presented in the scientific research of Yu. I. Shokin, V.P. Potapov [5].

To create an information model of the territory, such products as Infraworks 360, Civil $3 \mathrm{D}$ of the Autodesk company have become widespread, which help to use various data sources (raster data, shapefiles, 3D models, SQL databases, etc.) to model the territory.

Also, at the concept stage of a territory development project, building information modeling technologies can be used to create an information model of an object with its subsequent export to an information model of a territory (Fig. 2). Such appropriate software systems as Revit (software product of Autodesk), Archicad of Graphisoft, Allplan, Renga, etc. are used as technologies of buildings' information modeling [6]. In some products, for example, in Revit, there is functionality for creating a territory for a construction site, but there is no reference to a geographic coordinate system, which is not convenient when creating a territory, since the accuracy of the relative position of territory objects is important here. 

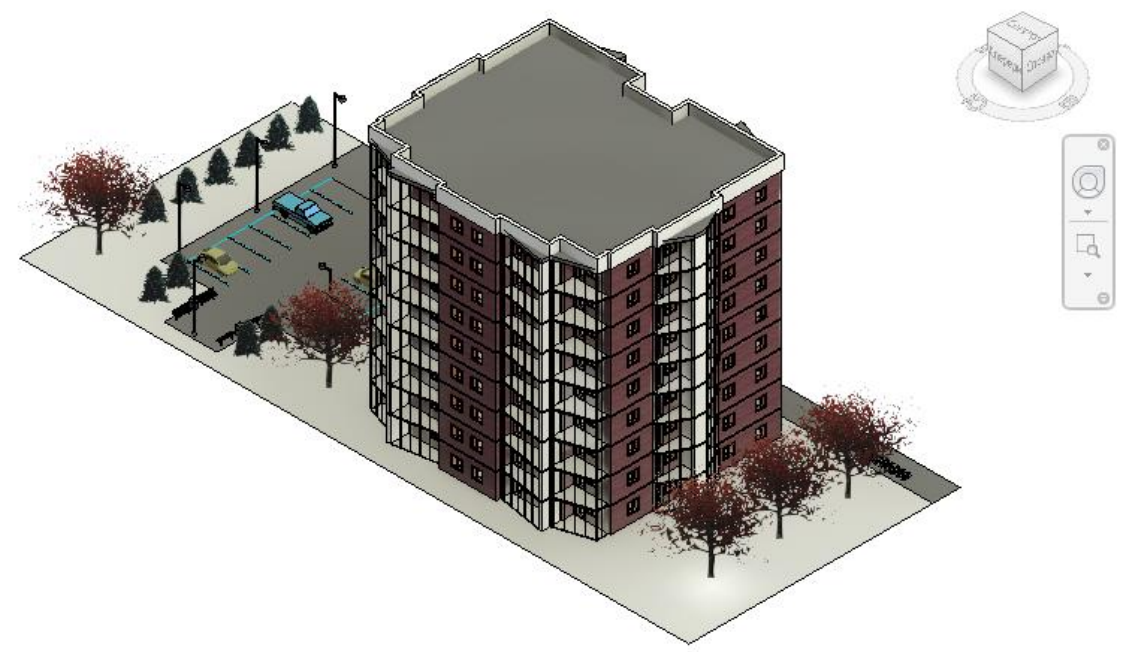

Fig. 2. Information model of the building and the territory of the construction site, made in Revit program

At the design and working documentation development stage, the main processes are the processes of acceptance, justification and presentation of design solutions. For this range of tasks, the most effective are:

- Building information modeling technologies;

- Geoinformation technologies;

- Technologies of territorial information modeling.

The most important are the issues of combining information modeling technologies and geoinformation technologies $[7,8]$. At the moment, there are several information systems that make it possible to combine architectural, engineering, organizational and technical solutions with geo-referenced objects of the territory, for example, Autodesk software systems (Infraworks 360, Civil 3D). However, when importing a structure information model into the Infraworks 360 environment, Civil 3D, there is currently no possibility of analyzing and adjusting the parameters of the model elements (the model in this environment can only be moved and scaled), which does not correspond to the object information model definition as an information database of all presented elements of the model.

At the stages of construction and operation of construction objects, it becomes necessary to analyze the adjustment and update of the information model of the territory. Building information modeling technologies and territory information modeling technologies are also used to optimize these processes. At this stage, the issue of fullfledged work with information models of objects of the territory is also important, as at the previous stage.

When solving urban planning problems, it is necessary to take into account the sectoral affiliation of the territory objects, which can be enlarged as:

- Engineering infrastructure facilities;

- Objects of transport infrastructure;

- Buildings and structures on the territory.

Next, we will consider the issues of the efficiency of using information technologies using the example of transport infrastructure facilities.

At the stage of the transport infrastructure projects' concept, various information technologies are used: 
- Information systems for systematization and analysis of data when performing analysis of the existing state of the territory (systematization and analysis of sociological data, measurements of existing passenger and traffic flows).

- Information systems for forecasting passenger and traffic flows.

- Information technology for the transport systems' calculation and design.

- Technologies of territorial information modeling.

The effective use of information technology in solving urban planning problems can be represented in the form of the following concept (Fig. 3). In this case, geoinformation technologies are used to structure and present information on the objects of the territory, and to solve specific urban planning problems (computational problems, mathematical modeling, graphical representation, information modeling), special information technologies are used.
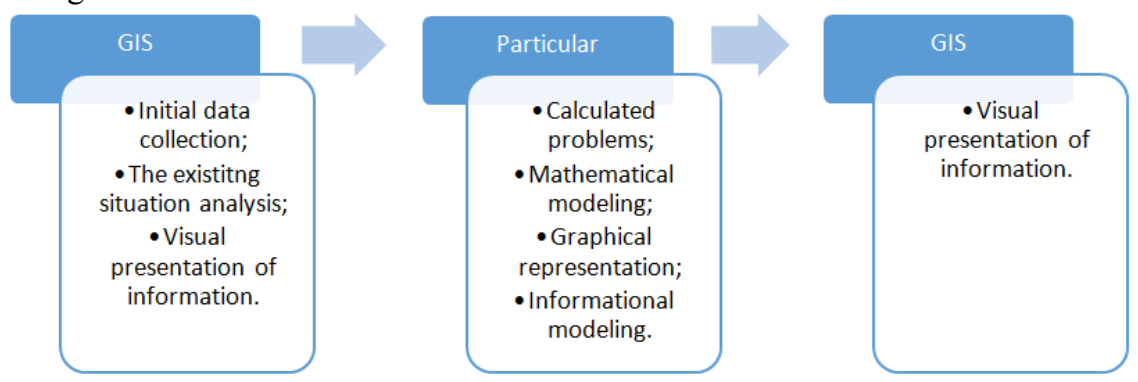

Fig. 3. The use of information technology in solving urban planning problems.

One of the current trends in the visual presentation technologies development is the use of interactive visualization of the BIM models using virtual and augmented reality technology $[9,10]$.

Also, a promising direction in the information technologies development in the field of solving urban planning problems is the use of artificial intelligence technology when creating an information model.

Based on the presented analysis of the use of information technologies in solving urban planning problems in the design of transport infrastructure facilities, the following levels of information technologies development influence on improving the quality of solving urban planning problems can be distinguished:

- High level of influence (level "1" implies that the development of this type of information technology has a significant impact on improving the quality of solving urban planning problems)

- Middle level (level "2" implies that the development of this type of information technology has a direct impact on improving the quality of solving urban planning problems)

- Low level of influence (level "3" implies that the development of this type of information technology has an insignificant effect on improving the quality of solving urban planning problems).

Table 1 presents a list of information technologies that affect the quality of solving urban planning problems.

The proposed systematization of the information technologies influence on improving the quality of solving urban planning problems makes it possible to use the considered criteria when planning the use of information systems in investment and government projects. 
Table 1. Levels of information technologies development influence on improving the quality of solving urban planning problems

\begin{tabular}{|l|c|c|c|}
\hline \multicolumn{1}{|c|}{ Information Technology } & \multicolumn{3}{c|}{$\begin{array}{c}\text { Levels of information } \\
\text { technologies development } \\
\text { influence on improving the } \\
\text { quality of solving urban } \\
\text { planning problems }\end{array}$} \\
\cline { 2 - 4 } & \multicolumn{2}{|c|}{$\mathbf{2}$} & $\mathbf{3}$ \\
\hline GIS & + & & \\
\hline Territory information modeling & + & & \\
\hline Building Information Modeling & & + & \\
\hline $\begin{array}{l}\text { Combination of building information modeling } \\
\text { technology and GIS }\end{array}$ & + & & \\
\hline $\begin{array}{l}\text { Database Management Systems Technologies } \\
\text { (DMST) }\end{array}$ & & + & \\
\hline Virtual and augmented reality technologies & + & & \\
\hline Artificial intelligence systems & + & & \\
\hline
\end{tabular}

\section{Conclusion}

The prospects of the most qualitative result in solving urban planning problems using information technologies are the most probable taking into consideration the current pace of information technologies development. The task of architects and urban planners is to choose the most effective ways of using and combining information technologies when performing the appropriate processes for solving urban planning problems.

\section{References}

1. Yu.B. Baranov, A.M. Berlyant, E.G. Kapralov, A.V. Koshkarev, B.B. Serapinas, Yu.A. Filippov, Geoinformatics. Explanatory dictionary of basic terms (GISAssociation, Moscow, 1999).

2. S. Shekar, H. Hiong, Enciclopedia of GIS (Springer, New York, 2008).

3. BC 333.1325800.2017 Building Information Modeling. Rules for the formation of an information model of objects at various stages of the life cycle. (Valid until 07/01/2021. Instead, approved and put into effect BC 333.1325800.2020 (Order of the Ministry of Construction, Housing and Communal Services of the Russian Federation dated 31.12.2020 N 928/pr).

4. BC 333.1325800.2020 Building Information Modeling. Rules for the formation of an information model of objects at various stages of the life cycle. (BC revision 333.1325800.2017 Building Information Modeling. Rules for the formation of an information model of objects at various stages of the life cycle).

5. Yu.I. Shokin, V.P. Potapov, Computational technologies 20 (5), 175-213 (2015).

6. Yu.N. Zgoda, K.A. Shumilov, Problems and prospects of automated construction of interactive visualization of information models of buildings Autodesk Revit and Renga, BIM-modeling in the tasks of construction and architecture: materials of the II Intern. scientific and practical conf. SPb., SPbGASU, 118-123 (2019).

7. E.A. Serova, L.A. Shilova, Scientific and Technical Bulletin of the Volga Region 2, (2019). 
8. V.P. Potapov, V.N. Oparin, Development of the theory and methods of creating dynamic geoinformation systems with a computing core for estimating the parameters of movements and the stress-strain state of the Earth's crust based on heterogeneous complex observations, Geomechanical fields and processes: experimental and analytical studies of the formation and development of focal zones of catastrophic events in mining and technical and natural systems 2, 220-245 (Novosibirsk, Publishing House of the Siberian Branch of the Russian Academy of Sciences, 2019).

9. A.V. Chistyakov, Bulletin of SUSU. Series "Construction and Architecture" 4 (17), 74-78 (2017). doi: 10.14529/build170411.

10. Yu.N. Zgoda, A.A. Semenov, K.A. Shumilov, Development of a photorealistic interactive visualization of a BIM model for virtual and augmented reality, New information technologies in architecture and construction: materials of the All-Russian scientific conference with international participation (Yekaterinburg, Ural state university of architecture and art, 2018). 